\title{
Pregnancy and parental leave among neurosurgeons and neurosurgical trainees
}

\author{
${ }^{*}$ Mihir Gupta, MD, ${ }^{1}$ Allison Reichl, BS, ${ }^{2}$ Luis Daniel Diaz-Aguilar, MD, ${ }^{1}$ Pate J. Duddleston, BS, ${ }^{3}$ \\ Jamie S. Ullman, MD, ${ }^{4}$ Karin M. Muraszko, MD, ${ }^{5}$ Shelly D. Timmons, MD, PhD, ${ }^{6}$ \\ Isabelle M. Germano, MD, MBA, ${ }^{7}$ Aviva Abosch, MD, PhD, ${ }^{8}$ Jennifer A. Sweet, MD, ${ }^{9,10}$ \\ Susan C. Pannullo, MD, ${ }^{11}$ Deborah L. Benzil, MD,12 and Sharona Ben-Haim, MD1
}

1Department of Neurosurgery and ${ }^{2}$ School of Medicine, University of California, San Diego, La Jolla, California; ${ }^{3}$ Department of Neurosurgery, Mercer University School of Medicine, Savannah, Georgia; ${ }^{4}$ Department of Neurosurgery, Donald and Barbara Zucker School of Medicine at Hofstra/Northwell, Hempstead, New York; ${ }^{5}$ Department of Neurosurgery, University of Michigan, Ann Arbor, Michigan; ${ }^{6}$ Department of Neurosurgery, IU Health Neuroscience Center, Indiana University, Indianapolis, Indiana; ${ }^{7}$ Department of Neurosurgery, Icahn School of Medicine at Mount Sinai, Mount Sinai Health System, New York, New York; ${ }^{8}$ Department of Neurosurgery, University of Nebraska Medical Center, Omaha, Nebraska; ' ${ }^{2}$ Department of Neurosurgery, University Hospitals Cleveland Medical Center, Cleveland, Ohio; ${ }^{10}$ Department of Neurosurgery, Case Western Reserve University, Cleveland, Ohio; ${ }^{11}$ Department of Neurological Surgery, Weill Medical College of Cornell University, New York, New York; and ${ }^{12}$ Department of Neurosurgery, The Cleveland Clinic Foundation, Cleveland, Ohio

OBJECTIVE Despite recently heightened advocacy efforts relating to pregnancy and family leave policies in multiple surgical specialties, no studies to date have described female neurosurgeons' experiences with childbearing. The AANS/ CNS Section of Women in Neurosurgery created the Women and Pregnancy Task Force to ascertain female neurosurgeons' experiences with and attitudes toward pregnancy and the role of family leave policies.

METHODS A voluntary online 28-question survey examined the pregnancy experiences of female neurosurgeons and perceived barriers to childbearing. The survey was developed and electronically distributed to all members of the American Association of Neurological Surgeons and Congress of Neurological Surgeons who self-identified as female in February 2016. Responses from female resident physicians, fellows, and current or retired practicing neurosurgeons were analyzed.

RESULTS A total of 126 women (20.3\%) responded to the survey; 57 participants (49\%) already had children, and 39 (33\%) planned to do so. Participants overwhelmingly had or planned to have children during the early practice and senior residency years. The most frequent obstacles experienced or anticipated included insufficient time to care for newborns ( $47 \%$ of women with children, $92 \%$ of women planning to have children), discrimination by coworkers $(31 \%$ and $77 \%$, respectively), and inadequate time for completion of board requirements (18\% and $51 \%$, respectively). There was substantial variability in family leave policies, and a minority of participants (35\%) endorsed the presence of any formal policy at their institution. Respondents described myriad unique challenges associated with pregnancy and family leave.

CONCLUSIONS Pregnancy and family leave pose significant challenges to the recruitment, retention, and advancement of women in neurosurgery. It is thus imperative to promote clear family leave policies for trainees and practitioners, address discrimination surrounding these topics, and encourage forethought and flexibility to tackle obstacles inherent in pregnancy and the early stages of child rearing.

https://thejns.org/doi/abs/10.3171/2020.2.JNS193345

KEYWORDS family leave; pregnancy; surgical training; surgery; neurosurgery; gender

ABBREVIATIONS AANS = American Association of Neurological Surgeons; ABNS = American Board of Neurological Surgery; CNS = Congress of Neurological Surgeons; WINS $=$ Women in Neurosurgery.

SUBMITTED December 11, 2019. ACCEPTED February 18, 2020.

INCLUDE WHEN CITING Published online May 29, 2020; DOI: 10.3171/2020.2.JNS193345.

${ }^{*}$ M.G. and A.R. contributed equally to this work. 
$\mathrm{T}$ HE Women in Neurosurgery (WINS) organization was established 30 years ago to promote the inclusion and advancement of women in the field and in 2014 was recognized as a joint section of the American Association of Neurological Surgeons (AANS) and Congress of Neurological Surgeons (CNS). While female neurosurgeons remain a minority within the profession, the number of female neurosurgery residents has nearly tripled in the last 10 years, and the proportion of active residents who are women has increased from $11 \%$ to $18 \% .^{1,2}$ In the most recent application cycle, a remarkable $22 \%$ of neurosurgery residency applicants were women. ${ }^{3}$ In the past 2 years, women have been elected for the first time to lead the AANS, Society of Neurological Surgeons, and American Board of Neurological Surgery (ABNS). Despite these advances, neurosurgery remains one of the most predominantly male subspecialties in medicine, ${ }^{4}$ and attrition rates for women neurosurgery residents are almost double those of men. ${ }^{5}$

Across professions including medicine, increased female representation has heightened advocacy efforts relating to pregnancy and family leave policies. Universally, however, female surgeons have expressed dissatisfaction with the duration of maternity leave, stigma related to pregnancy, and unsupportive work environments. Some female surgeons even discourage female medical students from embarking on a surgical career, specifically because of the difficulties of managing motherhood and training or early career development. ${ }^{6}$ Therefore, in looking toward the future of attracting and maintaining a balanced workforce, consideration of neurosurgeons' family and caretaking responsibilities is imperative. In particular, the unique physiological circumstances surrounding pregnancy and caring for a newborn child merit special consideration.

Given these challenges, we conducted a nationwide survey to specifically ascertain female neurosurgeons' experiences with and attitudes toward pregnancy. The results of this served as a catalyst for an amendment to the recent $A B N S$ statement on family and medical leave. The goal of this paper was to report these survey results, evaluate the findings in the context of the growing literature on pregnancy during training and practice from other surgical specialties, and provide recommendations to advance a more equitable workforce.

\section{Methods \\ Survey Creation}

In February 2016, a voluntary 28-question survey was created by the Women and Pregnancy Task Force of the AANS/CNS Joint Section of Women in Neurosurgery. The task force was created to formulate a survey based on review of published surveys on pregnancy and family leave from other surgical and medical specialties. ${ }^{7-14}$ The survey questions were designed to examine the pregnancy experiences of female neurosurgeons and the perceived barriers to childbearing and caregiving that exist in the field of neurosurgery. The survey employed branch logic to direct respondents to unique question sets based on whether they already had children, planned to have children in the future, or did not plan to have children.
Respondents with children were asked about the number and timing of pregnancies, the nature of parental leave experienced with each pregnancy, and their attitudes surrounding the experience. Respondents without children were asked questions pertaining to either future reproductive plans or their reasons for electing not to have children. Participants were encouraged to describe answers and provide their opinions in free-text boxes throughout the survey. The survey instrument is available online (eFig. 2 in the Supplemental Data).

\section{Target Population and Survey Delivery}

The WINS, AANS, and CNS membership databases were used to identify all neurosurgeons who self-identified as female and either graduated from or were currently enrolled in neurosurgical residency in the United States. A total of 621 women were identified, including 208 resident physicians, 29 fellows, and 384 current or retired practicing neurosurgeons. The survey was created using the SurveyMonkey online platform, and the link emailed to all participants.

\section{Data and Analysis}

Participant demographics and survey responses were analyzed using descriptive statistics. To contextualize these data and achieve a more robust understanding of the participants' situations, qualitative comments were organized into themes by constant comparative analysis. Chi-square analysis was used to ascertain whether survey question responses were independent of whether participants had or were planning to have children. A p value $<0.05$ was considered statistically significant. Data were collected using Microsoft Excel and analyzed in RStudio version 1.2.1335.

\section{Results}

\section{Survey Population}

Overall, $126(20.3 \%)$ of 621 women responded to the survey. ${ }^{5}$ Of these, $108(85.7 \%)$ were currently practicing neurosurgery as residents, fellows, or faculty. The remaining $18(14.3 \%)$ included one individual who left the field to pursue a different specialty, another who had previously practiced abroad, and 16 unspecified. A total of $57(48.7 \%)$ participants reported having had children, 39 (33.3\%) reported planning to have children but not currently having them, and $21(17.9 \%)$ reported that they do not currently have children and do not plan to have them. Among participants planning to have children, $50 \%$ planned to have them during the early practice years, and $31.6 \%$ during the senior or chief residency years (Table 1).

\section{Timing of Pregnancy and Family Leave}

Women delivering their first child most commonly took $4-8$ weeks $(n=23,42.6 \%)$ or $8-12$ weeks $(n=14,25.9 \%)$ of time off from work. This was similar for the birth of the second child, whereas shorter durations of leave were taken for the third and fourth children (Fig. 1A). Participants stated that the duration of parental leave was inadequate in $42.9 \%$ of cases after the first child, $38.7 \%$ after the second 
TABLE 1. Characteristics of survey participants

\begin{tabular}{|c|c|}
\hline & No. of Participants (\%) \\
\hline \multicolumn{2}{|l|}{ Currently practicing $(n=126)$} \\
\hline Yes & $108(85.7)$ \\
\hline No & $18(14.3)$ \\
\hline \multicolumn{2}{|l|}{ Practice environment $(n=120)$} \\
\hline Still in training & $52(43.3)$ \\
\hline Academic practice & $28(23.3)$ \\
\hline $\begin{array}{l}\text { Large single-specialty private ( } \geq 5 \text { neuro- } \\
\text { surgeons sharing call) }\end{array}$ & $10(8.3)$ \\
\hline $\begin{array}{l}\text { Small single-specialty private ( }<5 \text { neuro- } \\
\text { surgeons sharing call) }\end{array}$ & $12(10)$ \\
\hline Hospital employee & $11(9.2)$ \\
\hline Multispecialty group & $7(5.8)$ \\
\hline \multicolumn{2}{|l|}{ Children $(n=117)$} \\
\hline Currently have children & $57(48.7)$ \\
\hline $\begin{array}{l}\text { Do not currently have children but plan } \\
\text { to have }\end{array}$ & $39(33.3)$ \\
\hline $\begin{array}{l}\text { Do not currently have children \& do not } \\
\text { plan to have }\end{array}$ & $21(17.9)$ \\
\hline \multicolumn{2}{|l|}{ No. of children $(n=56)$} \\
\hline 1 & $15(26.8)$ \\
\hline 2 & $31(55.4)$ \\
\hline 3 & $8(14.2)$ \\
\hline 4 & $2(3.5)$ \\
\hline \multicolumn{2}{|l|}{$\begin{array}{l}\text { Stage at which participants plan to have } \\
\text { children }(n=38)\end{array}$} \\
\hline Junior residency (yrs 1-3) & $5(13.2)$ \\
\hline Senior residency (yrs 4-6) & $9(23.7)$ \\
\hline Chief residency yr & $3(7.9)$ \\
\hline Early practice (yrs 1-5) & $19(50)$ \\
\hline Late practice (yrs $\geq 5$ ) & $2(5.3)$ \\
\hline
\end{tabular}

child, and $75 \%$ after the third child (Fig. 1B). The nature of the time taken included vacation time, paid and unpaid leave, and research time during training (Fig. 1C).

Participants who already had children most frequently gave birth to their first child during senior residency (postgraduate years $4-6, \mathrm{n}=19,33.9 \%$ ) or early practice (postresidency years $1-5, \mathrm{n}=18,32.1 \%$ ). Second children were most commonly born during early practice $(\mathrm{n}=12$, $38.7 \%$ ) or midcareer (postresidency years $\geq 5, \mathrm{n}=10$, $32.3 \%$ ). Third and fourth children were born exclusively in the early and midcareer stages (eFig. 1 in the Supplemental Data).

\section{Challenges to Pregnancy}

Among women who had children at the time of the survey, the most frequently reported obstacles surrounding pregnancy and childcare were insufficient time to care for newborns $(47.3 \%)$ and discrimination by coworkers (30.9\%). Additionally, $18.2 \%$ felt that they needed more time to fulfill board certification requirements. Among women planning to have children, compared with those who already had children, even higher proportions anticipated insufficient time off to care for a newborn $(92.3 \%, \mathrm{p}$ $<0.001)$, discrimination by coworkers $(76.9 \%, p<0.001)$, and insufficient time to fulfill board certification requirements $(51.3 \%, \mathrm{p}<0.001)$ (Table 2).

Significant proportions of both women planning to have children and those not planning to do so anticipated challenges to implementing family leave policies, including stigma/discrimination against female neurosurgeons (35.9\% of women planning to have children and $14.3 \%$ of those not planning), loss of professional advancement opportunities (25.6\% and $38.1 \%$, respectively), and increased workloads for coworkers (33.3\% each). Women who already had or were planning to have children more frequently endorsed stigma/discrimination and less frequently endorsed lost professional advancement than women not planning to have children ( $\mathrm{p}=0.043$ and 0.032 , respectively). Notably, $30.9 \%$ of women who already had children endorsed no obstacles to pregnancy or childcare (Table 2).

Women not planning to have children were asked about factors that played a role in this decision. The majority endorsed that their work environment played a role, while many cited conflicts with career goals and unsupportive practice environments (eTable 1 in the Supplemental Data).

\section{Awareness and Existence of Family Leave Policies}

A minority of participants (34.8\%) reported the presence of a family leave policy at their hospital or practice. Although awareness of these policies was highest among women who had children, $41.8 \%$ of respondents in this group were unsure whether such a policy existed, compared with $64.1 \%$ among those planning to have children and $48.7 \%$ overall (eTable 2 in the Supplemental Data).

\section{Qualitative Themes}

Participants were invited to further describe their experiences in their own words. Several consistent themes emerged from these descriptions. Family leave policies were highly variable between practice environments and in many cases absent. Furthermore, the presence of family leave policies did not always allow their utilization. Many participants described discrimination by coworkers and supervisors (Table 3). Participants poignantly described the tremendous physical challenges of simultaneously performing clinical and parental duties, often exacerbated by short recovery times (eTable 3 in the Supplemental Data). Several described the financial burden of unpaid leave forcing a return to work earlier than desired. Pregnancy and leave affected professional and training opportunities in several cases (eTable 4 in the Supplemental Data).

\section{Discussion}

Many female medical students, residents, and physicians still perceive that surgical specialties are incompatible with pregnancy and child rearing..$^{715,16}$ Female surgeons remain significantly less likely than their male counterparts to marry and have children, and this difference is especially pronounced in neurosurgery, ${ }^{7,16-18}$ a field with lengthy and intense residency training. Because women 
A

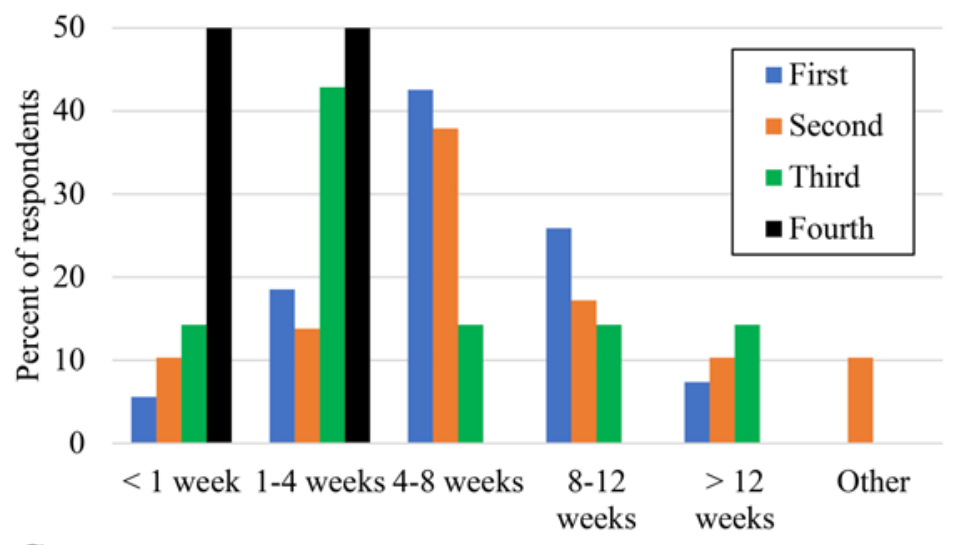

B

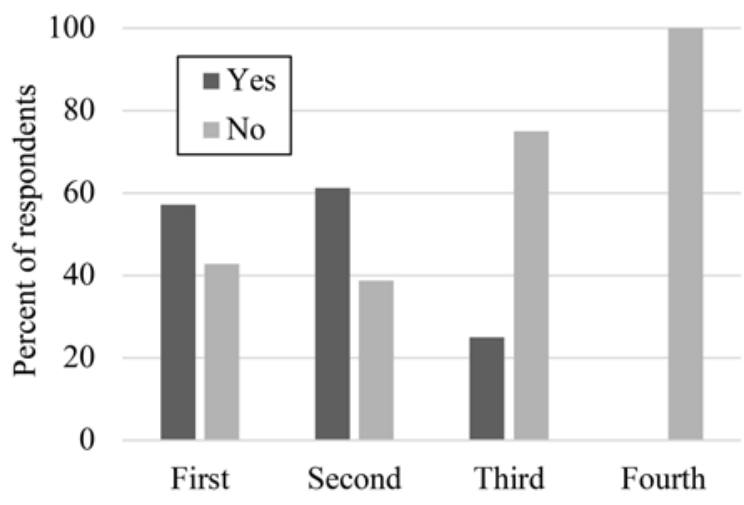

C

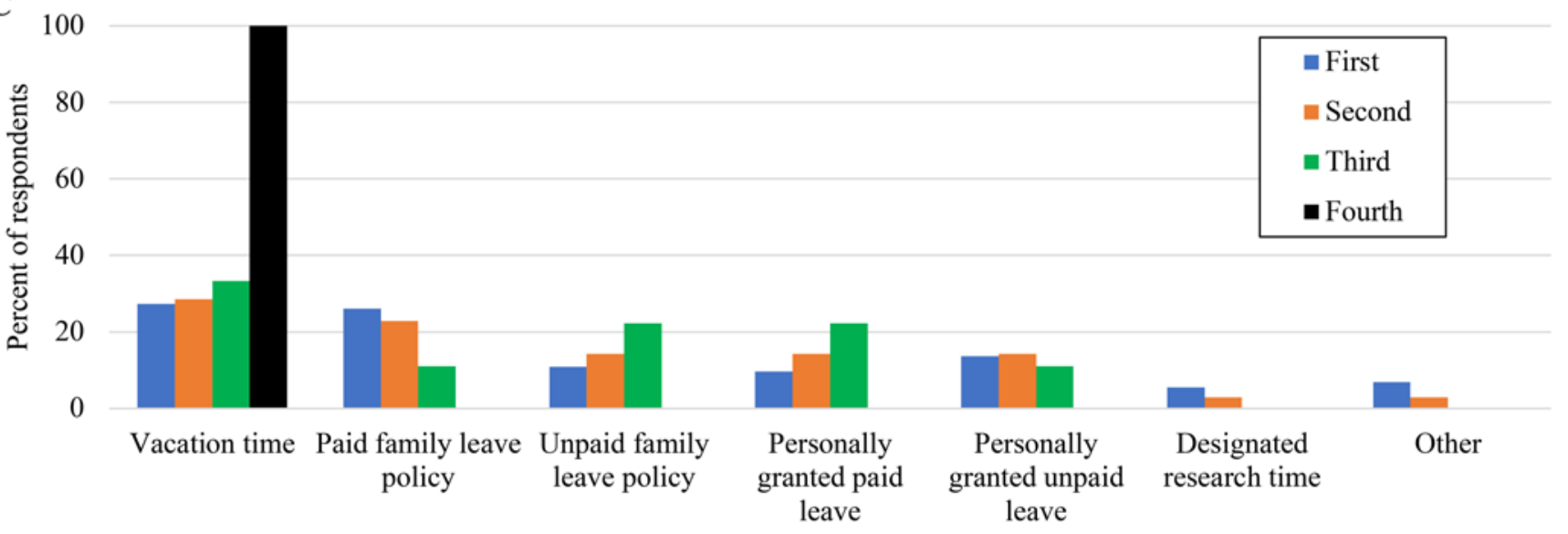

FIG. 1. A: Amount of time taken off for pregnancy and/or birth of each respective child. Other represents $3(10.3 \%)$ respondents whose first birth was twins. B: Whether the amount of time off was felt to be adequate for each child. C: Nature of the time taken off. Among first children other represents $2(2.7 \%)$ participants who took didactic classes, $2(2.7 \%)$ unspecified, and $1(1.4 \%)$ medical leave for pregnancy-related complications. Among second children, other represents 1 (2.9\%) participant who took medical leave for pregnancy-related complications.

still represent a small minority of neurosurgeons, ${ }^{2}$ issues related to pregnancy have received little attention despite the high potential for impact on graduate medical education, early practice, and board certification. This comprehensive survey, distributed by the WINS Task Force, helps understand the perceptions of female neurosurgeons surrounding pregnancy that will facilitate addressing barriers to women entering the neurosurgical workforce. This clearly represents an area that should be a key focus for all involved with recruiting, training, and certifying future neurosurgeons. Additionally, recent advocacy in the public sphere surrounding gender-related mistreatment has highlighted the timely need for re-evaluation of policies and practices to ensure equity, transparency, and responsiveness to issues of discrimination in the workplace.

Overt and covert discrimination from coworkers during and after their pregnancy was one common concern reported by female neurosurgeons in this survey. This is unsurprising, as women anticipate and experience gender discrimination in the surgical workplace more than their male counterparts. ${ }^{7,13,16-21}$ In a recent analysis of women in academic surgery departments, women were 10 times more likely than male faculty to perceive gender discrimination. ${ }^{7}$ Unfortunately, this discrimination often starts from the top. In a 2016 study of neurosurgical department leaders in Japan, 25\% of department chairs stated outright that they would be reluctant to hire female neurosurgeons ${ }^{17}$ Academic program directors perceive that becoming a parent negatively affects female trainees' work performance and well-being more than that of male trainees. ${ }^{22,23}$ Additionally, strife between same-level coworkers can likely be attributed to the fact that coverage for residents on parental leave is most often provided by coresidents, usually without compensation or schedule accommodation. ${ }^{10,24,25}$ The degree to which self-imposed pressures and feelings of guilt surrounding missed coverage may add to this burden and whether such attitudes differ between women and men remain unknown. The creation and promotion of consistent leave policies within programs may alleviate much of the uncertainty surrounding these salient issues.

Perception of pregnancy-related challenges by those currently contemplating having children was significantly higher than even that reported by those who had children, 
TABLE 2. Obstacles faced or anticipated surrounding pregnancy, childcare, and family leave policies

\begin{tabular}{|c|c|c|c|c|}
\hline \multirow[b]{2}{*}{ Survey Question } & \multicolumn{3}{|c|}{ Children* } & \multirow[b]{2}{*}{ p Value } \\
\hline & $\begin{array}{l}\text { Already Have } \\
\quad(n=55)\end{array}$ & $\begin{array}{l}\text { Planning to } \\
\text { Have }(n=39)\end{array}$ & $\begin{array}{l}\text { Not Planning to } \\
\text { Have }(n=21)\end{array}$ & \\
\hline \multicolumn{5}{|c|}{ Obstacle(s) faced or anticipated surrounding pregnancy or childcare $\dagger$} \\
\hline Not enough time off to care for newborn & $26(47.3)$ & $36(92.3)$ & NA & $<0.001$ \\
\hline Discrimination by coworkers & $17(30.9)$ & $30(76.9)$ & NA & $<0.001$ \\
\hline Needed extra time to fulfill ABNS requirements & $10(18.2)$ & $20(51.3)$ & NA & $<0.001$ \\
\hline Physical difficulty in performing clinical duties & $3(5.5)$ & $1(2.6)$ & NA & NT \\
\hline Lost training opportunities & $3(5.5)$ & 0 & NA & NT \\
\hline Pressure to not burden colleagues & $3(5.5)$ & 0 & NA & NT \\
\hline Loss of pay during time off & $1(1.8)$ & $2(5.1)$ & NA & NT \\
\hline Requirement to make up time in training & $1(1.8)$ & $1(2.6)$ & NA & NT \\
\hline No obstacles & $17(30.9)$ & $7(17.9)$ & NA & 0.156 \\
\hline \multicolumn{5}{|c|}{ Single biggest challenge for female neurosurgeons regarding family leave policiesł } \\
\hline Social stigma or discrimination for taking time off & $21(38.2)$ & $14(35.9)$ & $3(14.3)$ & 0.043 \\
\hline Increased workload for coworkers & $18(32.7)$ & $13(33.3)$ & $7(33.3)$ & 0.975 \\
\hline Loss of income & $7(12.7)$ & $2(5.1)$ & 0 & NT \\
\hline Lost or delayed professional advancement & $6(10.9)$ & $10(25.6)$ & $8(38.1)$ & 0.032 \\
\hline Requirement to make up time in training & $1(1.8)$ & 0 & 0 & NT \\
\hline All of the above & $1(1.8)$ & 0 & $2(9.5)$ & NT \\
\hline No anticipated challenges & $1(1.8)$ & 0 & $1(4.8)$ & NT \\
\hline
\end{tabular}

NA = not applicable; NT = not tested.

Boldface type indicates statistical significance.

* Data are categorized by whether participants already have children or are planning to do so. Values are presented as number of participants (\%).

$\dagger p$ values for this question represent comparisons between women who already have children and those planning to have children.

$\ddagger p$ values for this question represent comparisons between women not planning to have children and the combined responses of those who already have or are planning to have children.

some even decades earlier. It is concerning that, nearly 60 years after the first female neurosurgeon achieved board certification in the US, this issue remains such a serious concern. ${ }^{4}$ One possible explanation is that younger female neurosurgeons may have observed the experiences of other women during and after pregnancy and the many obstacles they faced. Interestingly, more than $30 \%$ of participants in our cohort who already had children endorsed no obstacles relating to pregnancy or childcare. Additionally, several obstacles were perceived more frequently by women planning to have children than those who already had them (Table 2). Although these findings should be interpreted with caution in a study of this size, this highlights a possible gap between perceptions and lived experiences surrounding pregnancy and the urgent need for further dialogue in the professional community.

Having insufficient time to care for newborns was reported by nearly half $(47 \%)$ of the respondents in our study. Adequate parental bonding with newborns has been demonstrated to be critical for their psychological development and correlates with decreased infant mortality. ${ }^{26}$ A key part of postnatal care is breastfeeding, which promotes healthy immune systems in infants and can help prevent the development of asthma, autoimmune disorders, neurodevelopmental problems, gastrointestinal problems, and sudden infant death syndrome. ${ }^{27}$ Insufficient time away from work during this period correlates with maternal depression, negative interactions with infants, low self-esteem, and strained marital relationships. ${ }^{26-28}$ Unfortunately, insufficient parental leave has the potential for greater disruption in subsequent years for health-related problems.

For neurosurgeons in our study, the desire for additional caregiving time is complicated by the competing concern of losing professional advancement opportunities. Several described losing training opportunities, feeling pressure not to burden colleagues, or experiencing physical difficulty performing clinical duties. Across academic disciplines, studies have shown that program directors believe maternity leave leads to insufficient clinical exposure, and women frequently need to extend their residency duration in order to compensate for maternity leave ${ }^{8,29}$ Female thoracic surgeons who felt pressured to resume their clinical responsibilities were found to utilize significantly less maternity leave time than those who did not feel pressured. ${ }^{14}$ Such a "motherhood penalty" has been documented for professional women across modern society. ${ }^{30} \mathrm{In}$ academic neurosurgery, it has been demonstrated that male neurosurgeons consistently outperform women in terms of productivity, as defined by traditional measures, including career duration, mean articles published, citations, and $h$ index. ${ }^{31,32}$ It is thus imperative to address any impediments to professional advancement and productivity that may affect a significant portion of the workforce. Furthermore, 


\section{TABLE 3. Representative comments regarding the decision to have children, family leave policies, and interactions with coworkers during family leave}

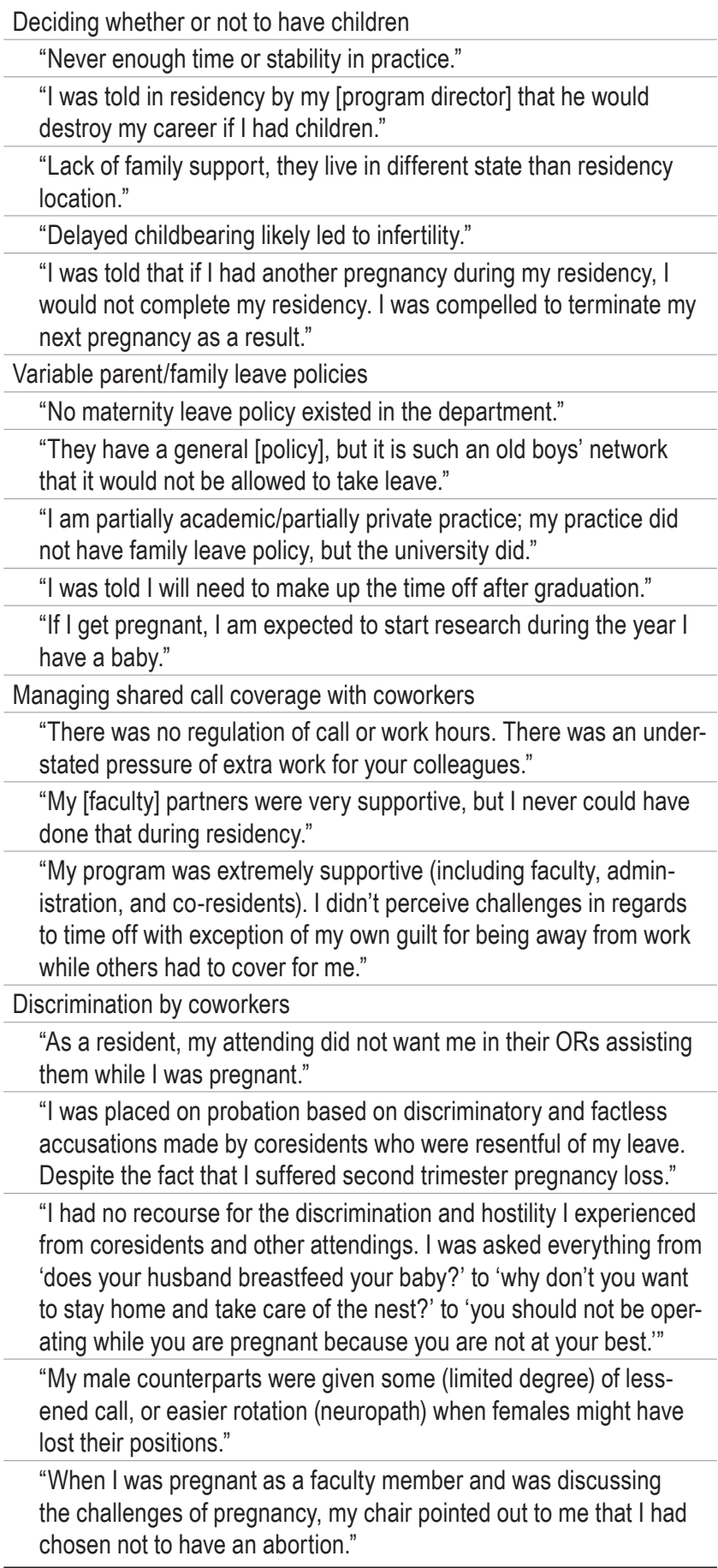

$\mathrm{OR}=$ operating room

gender and racial diversity in healthcare has been shown to improve patient outcomes and quality of care..$^{33-35}$

Certification by the ABNS requires collecting and submitting 125 cases during an 18 -month period within 4 years of completing residency. Our findings show that female neurosurgeons most frequently bear children during senior residency or early practice, necessitating flexibility in completing board certification requirements for candidates who have had children during this period. The results of this survey led to a recent statement from the ABNS permitting extension of the board eligibility period on a case-by-case basis to accommodate family leave and related circumstances (eFig. 3 in the Supplemental Data).

Beyond psychological and interpersonal stressors, physical requirements for pregnant neurosurgeons can be particularly demanding, as expressed by some of the respondents in our survey. Prior studies have reported that the majority of surgical residents work late into their pregnancy ( $>36$ weeks' gestation) and maintain 80-hour work weeks or greater when pregnant ${ }^{9,10,12}$ despite increased demands for rest and proper nutrition during pregnancy. Notably, pregnancy complication rates among female surgeons are higher than those in the lowest income brackets in the United States, likely due to a combination of physical stressors and the advanced maternal age typical of surgeons' pregnancies. ${ }^{36}$ Exposure to ionizing radiation during pregnancy, which can be a part of neurosurgical practice, is an additional concern.

One promising solution for managing female neurosurgeons' childcare stress would be the gender-neutral provision and encouragement of family leave. This not only addresses a critical need but also reinforces a view of parenting as a shared responsibility among both men and women. ${ }^{37}$ Female physicians still shoulder the majority of caregiving responsibilities ${ }^{8,38}$ and take significantly longer parental leave than their non-childbearing partners. ${ }^{11}$ In one study, male thoracic surgeons took an average of only 5 days of parental leave. ${ }^{14}$ Although these findings are also attributable to factors such as personal choice and the need for postpartum physical recuperation, a balanced workforce in neurosurgery will only be achieved through careful consideration of family leave policies for men and women. Anecdotal evidence also suggests that while women, by definition, must schedule or make arrangements for birthing and maternity leave, men frequently take ad hoc time off at the time of their partner's delivery, which is a suboptimal approach.

This study is subject to the limitations of any survey. The survey response rate of $20.3 \%$ raises the prospect of response bias, particularly with respect to participants' written responses (Table 3). As the survey was purely voluntary, it is possible that the female neurosurgeons who chose to respond are particularly passionate about issues surrounding pregnancy. In order to protect confidentiality, we deferred asking potentially identifying information such as the specific year during residency training that participants are currently in or had each of their children. Furthermore, our characterization of attitudes toward parental leave in neurosurgery would certainly be more robust if male physicians had also been surveyed. Although both male and female neurosurgeons reviewed the survey results, the survey was formulated by the WINS Task Force comprising female members. Future studies should also take into account extenuating life circumstances (e.g., elder caretaking, maternal medical issues) - issues that were beyond the scope of the task force. This study also relates 
TABLE 4. Recommendations regarding family leave policies based on survey results

\begin{tabular}{|c|c|}
\hline Recommendation & Reason \\
\hline $\begin{array}{l}\text { All training programs should have formal writ- } \\
\text { ten family leave policies, and trainees should } \\
\text { receive direct education on these policies. }\end{array}$ & $\begin{array}{l}\text { Awareness of existing family leave policies was remarkably low in our study ( }<32 \% \text { overall). This } \\
\text { trend is characteristic of many surgical specialties }{ }^{30,33,35,36} \text { and reflects the need for heightened } \\
\text { transparency regarding leave policies from program directors. }\end{array}$ \\
\hline $\begin{array}{l}\text { Training programs, board-certifying entities, } \\
\text { and other professional associations should } \\
\text { strive to endorse paid family leave for parents } \\
\text { of all genders. }\end{array}$ & $\begin{array}{l}\text { The financial impact of a new child makes paid leave a necessity. The FMLA of } 1993 \text {, which } \\
\text { protects } 12 \text { weeks of unpaid leave for eligible American employees, is insufficient. Whereas of- } \\
\text { ficial statements regarding family leave from many surgical associations are vague, statements } \\
\text { from the ACOS }{ }^{37} \text { and the ACOG explicitly support paid leave, with the latter endorsing at least } 6 \\
\text { weeks of full benefits and paid leave. }{ }^{38} \text { We encourage neurosurgical organizations to follow suit } \\
\text { in endorsing paid leave for at least } 6 \text { weeks, tailored to the needs of each program, with flex- } \\
\text { ibility in scheduling upon return to work to help meet the demands of caring for a newborn. }\end{array}$ \\
\hline $\begin{array}{l}\text { Institutions should consider establishing } \\
\text { accessible lactation rooms, childcare facilities, } \\
\text { and incentivizing coverage of call duties. }\end{array}$ & $\begin{array}{l}\text { These changes would not only manage stressors for female neurosurgeons but also allow them to } \\
\text { maintain higher academic productivity. }\end{array}$ \\
\hline $\begin{array}{l}\text { The ABNS should allow for flexible options to } \\
\text { complete board requirements. }\end{array}$ & $\begin{array}{l}\text { Our data indicate that female neurosurgeons are most likely to bear children during their senior } \\
\text { residency or early practice years, and this timing has high potential to disrupt fulfillment of } \\
\text { requirements for board certification. Findings from our study led to a recent statement on family } \\
\text { leave from the ABNS. This statement recognizes that family leave makes it difficult for candi- } \\
\text { dates to meet the certification requirements of collecting } 125 \text { consecutive cases in } 18 \text { months } \\
\text { and submitting completed applications within } 4 \text { years of residency training completion. The } \\
\text { statement permits the ABNS directors to extend these time periods on a case-by-case basis. }{ }^{39}\end{array}$ \\
\hline $\begin{array}{l}\text { These recommendations should pertain } \\
\text { equally to same-gender couples, as well as in } \\
\text { cases of adoption. }\end{array}$ & $\begin{array}{l}\text { Formal adoption leave is less prevalent in surgical programs than either maternity or paternity } \\
\text { leave }{ }^{40} \text { but should not be marginalized, as family-life upheaval is similar for adoptive parents. }\end{array}$ \\
\hline
\end{tabular}

ACOG = American College of Obstetricians and Gynecologists; ACOS = American College of Surgeons; FLMA = Family and Medical Leave Act.

most directly to "traditional" heterosexual monogamous relationships, an assumption that does not fully reflect the nuanced diversity of family structures present in our society.

Our study illustrates the need for neurosurgery training programs to recognize the challenges associated with pregnancy and proactively address them. The majority of women surveyed reported that they either currently have children or would like to welcome children into their lives. However, they have legitimate concerns over whether having and raising children is compatible with neurosurgery training. ${ }^{19}$ To address the concerns of women trainees and faculty, we offer several important recommendations (Table 4). It is imperative for all training programs to institute written family leave policies. Whereas the federal Family and Medical Leave Act supports 12 weeks of unpaid leave, neurosurgical organizations should advocate for paid leave. Organizations such as the American College of Obstetricians and Gynecologists endorse full benefits and paid leave for a period of 6 weeks. Based on these precedents, it is our recommendation that neurosurgeons be offered paid leave for a minimum of 6 weeks. For residents and fellows, maximal efforts should be made to encourage flexibility in scheduling on return to work to help meet the distinctive demands of caring for a newborn during the first 3 months of life, recognizing the needs of individual programs. These policies should pertain equally to nontraditional families and cases of adoption. Institutions should consider establishing accessible childcare facilities and lactation rooms, with attention to the unique circumstances surrounding an operating room environment.
All neurosurgical trainees, regardless of bearing children or other training interruptions, are expected to meet the requirements instituted by the ABNS prior to commencement. Thus, to help individuals necessitating maternity, family, or medical leave achieve a timely graduation, a degree of flexibility in the scheduling of rotations is encouraged. Our findings regarding the frequency of perceived discrimination highlight the critical need for programs to actively communicate these supportive policies to current and prospective women neurosurgeons. In addition, the ABNS should consider the question globally of the specific minimum time requirements given the various medical, family, educational, and personal leave experienced by all residents in training.

Our results raise many additional questions that merit further study. These include individual-level factors such as the proportion of women receiving support from a spouse, partner, and/or other family members; the relative contributions of different family members; and the experiences of single parents. The gestational age until which female neurosurgeons continue operating while pregnant remains unknown. The level of childcare support and other resources available may differ between practices of different sizes, rural or urban location, and academic or private settings. Future studies should also seek to compare experiences following the ABNS family leave statement with those at the time of our 2016 survey.

\section{Conclusions}

Challenges surrounding pregnancy and family leave 
remain consequential for female neurosurgeons, particularly during their senior residency and early practice years. It is imperative that all neurosurgical practices formulate clear paid family leave policies and encourage flexibility in order to address obstacles such as discrimination and inadequate caregiving time. The proposed recommendations are intended to promote the recruitment of a diverse population of neurosurgical residents, retain workforce talent, and wholly improve work-life balance for surgeons of all genders.

\section{Acknowledgments}

We thank the survey participants for their time and thoughtful contributions. The creation of the survey and subsequent advocacy efforts would not have been possible without the tremendous efforts of the individuals in the AANS/CNS Joint Section on Women in Neurosurgery. We sincerely thank the AANS, CNS, and ABNS leadership for guidance in reviewing survey content and distributing the survey among their membership.

\section{References}

1. ACGME. Data Resource Book Academic Year 2007-2008. Accreditation Council for Graduate Medical Education; 2008.

2. ACGME. Data Resource Book Academic Year 2017-2018. Accreditation Council for Graduate Medical Education; 2018.

3. AAMC. Residency Applicants to ACGME-Accredited Programs by Specialty and Sex, 2018-2019. Association of American Medical Colleges; 2018.

4. Abosch A, Rutka JT. Women in neurosurgery: inequality redux. J Neurosurg. 2018;129(2):277-281.

5. Agarwal N, White MD, Pannullo SC, Chambless LB. Analysis of national trends in neurosurgical resident attrition. $J$ Neurosurg. 2019;131(5):1668-1673.

6. Rangel EL, Smink DS, Castillo-Angeles M, et al. Pregnancy and motherhood during surgical training. JAMA Surg. 2018;153(7):644-652.

7. Cochran A, Hauschild T, Elder WB, et al. Perceived genderbased barriers to careers in academic surgery. Am J Surg. 2013;206(2):263-268.

8. Dixit A, Feldman-Winter L, Szucs KA. Parental leave policies and pediatric trainees in the United States. J Hum Lact. 2015;31(3):434-439.

9. Eskenazi L, Weston J. The pregnant plastic surgical resident: results of a survey of women plastic surgeons and plastic surgery residency directors. Plast Reconstr Surg. 1995;95(2):330-335.

10. Gabbe SG, Morgan MA, Power ML, et al. Duty hours and pregnancy outcome among residents in obstetrics and gynecology. Obstet Gynecol. 2003;102(5 Pt 1):948-951.

11. Holliday EB, Ahmed AA, Jagsi R, et al. Pregnancy and Parenthood in Radiation Oncology, Views and Experiences Survey (PROVES): results of a blinded prospective trainee parenting and career development assessment. Int J Radiat Oncol Biol Phys. 2015;92(3):516-524.

12. Merchant S, Hameed M, Melck A. Pregnancy Among Residents Enrolled in General Surgery (PREGS): a survey of residents in a single Canadian training program. Can J Surg. 2011;54(6):375-380.

13. Park J, Minor S, Taylor RA, et al. Why are women deterred from general surgery training? Am J Surg. 2005;190(1):141146.

14. Pham DT, Stephens EH, Antonoff MB, et al. Birth trends and factors affecting childbearing among thoracic surgeons. Ann Thorac Surg. 2014;98(3):890-895.

15. Bellini MI, Graham Y, Hayes C, et al. A woman's place is in theatre: women's perceptions and experiences of working in surgery from the Association of Surgeons of Great Britain and Ireland women in surgery working group. BMJ Open. 2019;9(1):e024349.

16. Mulcahey MK, Nemeth C, Trojan JD, O'Connor MI. The perception of pregnancy and parenthood among female orthopaedic surgery residents. J Am Acad Orthop Surg. 2019;27(14):527-532.

17. Fujimaki T, Shibui S, Kato Y, et al. Working conditions and lifestyle of female surgeons affiliated to the Japan Neurosurgical Society: findings of individual and institutional surveys. Neurol Med Chir (Tokyo). 2016;56(11):704-708.

18. Steklacova A, Bradac O, de Lacy P, Benes V. E-WIN Project 2016: Evaluating the current gender situation in neurosurgery across Europe-an interactive, multiple-level survey. World Neurosurg. 2017;104:48-60.

19. Dixon A, Silva NA, Sotayo A, Mazzola CA. Female medical student retention in neurosurgery: a multi-faceted approach. World Neurosurg. 2019;122:245-251.

20. Salles A, Milam L, Cohen G, Mueller C. The relationship between perceived gender judgment and well-being among surgical residents. Am J Surg. 2018;215(2):233-237.

21. Zhuge Y, Kaufman J, Simeone DM, et al. Is there still a glass ceiling for women in academic surgery? Ann Surg. 2011;253(4):637-643.

22. Acai A, Steyn C, Reid SE, Sonnadara RR. A solution to gender inequity in surgery? Better caregiving policies. Can J Surg. 2018;61(1):6-7.

23. Sandler BJ, Tackett JJ, Longo WE, Yoo PS. Pregnancy and parenthood among surgery residents: results of the first nationwide survey of general surgery residency program directors. J Am Coll Surg. 2016;222(6):1090-1096.

24. Davis JL, Baillie S, Hodgson CS, et al. Maternity leave: existing policies in obstetrics and gynecology residency programs. Obstet Gynecol. 2001;98(6):1093-1098.

25. Hariton E, Matthews B, Burns A, et al. Pregnancy and parental leave among obstetrics and gynecology residents: results of a nationwide survey of program directors. Am J Obstet Gynecol. 2018;219(2):199.e1-199.e8.

26. Burtle A, Bezruchka S. Population health and paid parental leave: what the United States can learn from two decades of research. Healthcare (Basel). 2016;4(2):4.

27. Greenfield JC, Klawetter S. Parental leave policy as a strategy to improve outcomes among premature infants. Health Soc Work. 2016;41(1):17-23.

28. Dagher RK, McGovern PM, Dowd BE. Maternity leave duration and postpartum mental and physical health: implications for leave policies. J Health Polit Policy Law. 2014;39(2):369416.

29. Mayer KL, Ho HS, Goodnight JE Jr. Childbearing and child care in surgery. Arch Surg. 2001;136(6):649-655.

30. Kahn JR, García-Manglano J, Bianchi SM. The motherhood penalty at midlife: long-term effects of children on women's careers. J Marriage Fam. 2014;76(1):56-72.

31. Mueller C, Wright R, Girod S. The publication gender gap in US academic surgery. BMC Surg. 2017;17(1):16.

32. Shaikh AT, Farhan SA, Siddiqi R, et al. Disparity in leadership in neurosurgical societies: a global breakdown. World Neurosurg. 2019;123:95-102.

33. Cohen KL. Racial and ethnic disparities in health care. Ann Intern Med. 2005;142(2):154.

34. Roter DL, Hall JA, Aoki Y. Physician gender effects in medical communication: a meta-analytic review. JAMA. 2002;288(6):756-764.

35. Wallis CJ, Ravi B, Coburn N, et al. Comparison of postoperative outcomes among patients treated by male and female surgeons: a population based matched cohort study. BMJ. 2017;359:j4366.

36. Lerner LB, Stolzmann KL, Gulla VD. Birth trends and preg- 
nancy complications among women urologists. J Am Coll Surg. 2009;208(2):293-297.

37. Greenberg CC. Association for Academic Surgery presidential address: sticky floors and glass ceilings. J Surg Res. 2017;219:ix-xviii.

38. Kin C, Yang R, Desai P, et al. Female trainees believe that having children will negatively impact their careers: results of a quantitative survey of trainees at an academic medical center. BMC Med Educ. 2018;18(1):260.

39. Statement on Family and Medical Leave. American Board of Neurological Surgery. Accessed March 23, 2020. https://abns. org/family-and-medical-leave/

40. Weiss J, Teuscher D. What provisions do orthopaedic programs make for maternity, paternity, and adoption leave? Clin Orthop Relat Res. 2016;474(9):1945-1949.

\section{Disclosures}

Dr. Germano: consultant for Brainlab and Integra and direct stock ownership in Elminda and Surgical Theater. Dr. Sweet: consultant for Koh Young Inc.

\section{Author Contributions}

Conception and design: Ben-Haim, Gupta, Ullman, Muraszko, Timmons, Germano, Abosch, Sweet, Pannullo, Benzil. Acqui- sition of data: Ben-Haim, Gupta. Analysis and interpretation of data: all authors. Drafting the article: all authors. Critically revising the article: all authors. Reviewed submitted version of manuscript: all authors. Approved the final version of the manuscript on behalf of all authors: Ben-Haim. Statistical analysis: Ben-Haim, Gupta. Administrative/technical/material support: Ben-Haim, Gupta, Diaz-Aguilar, Duddleston. Study supervision: Ben-Haim, Ullman, Muraszko, Timmons, Germano, Abosch, Sweet, Pannullo, Benzil.

\section{Supplemental Information}

\section{Online-Only Content}

Supplemental material is available with the online version of the article.

Supplemental Data. https://thejns.org/doi/suppl/10.3171/ 2020.2.JNS193345.

\section{Correspondence}

Sharona Ben-Haim: University of California, San Diego, CA. sbenhaim@health.ucsd.edu. 